\title{
O KAIZEN COMO SISTEMA DE MELHORIA CONTÍNUA: UM ESTUDO DE CASO EM UMA INDÚSTRIA DE NUTRIÇÃO ANIMAL
}

Jorzimar Benhur Bresciani

jbenhurb@hotmail.com

Universidade Comunitária da

Região de Chapecó - Unochapecó,

Chapecó, Santa Catarina, Brasil

Fernanda Schwanke Bianchet fernandaschwanke@hotmail.com Universidade Comunitária da Região de Chapecó - Unochapecó, Chapecó, Santa Catarina, Brasil

\section{Micheli Zanetti}

eng.miche@unochapeco.edu.br Universidade Comunitária da Região de Chapecó - Unochapecó, Chapecó, Santa Catarina, Brasil

\section{Josiane Maria Muneron de} Mello

josimello@unochapeco.edu.br Universidade Comunitária da Região de Chapecó - Unochapecó, Chapecó, Santa Catarina, Brasil

\section{Marcelo Fabiano Costella}

costella@unochapeco.edu.br Universidade Comunitária da Região de Chapecó - Unochapecó, Chapecó, Santa Catarina, Brasil

\section{Francieli Dalcanton}

fdalcanton@unochapeco.edu.br Universidade Comunitária da Região de Chapecó - Unochapecó, Chapecó, Santa Catarina, Brasil

\section{RESUMO}

A demanda por alimentos destinados à nutrição animal tem aumentado com o passar dos anos, fazendo com que as indústrias invistam cada vez mais nos processos produtivos. Para melhorar a eficiência dos processos, a utilização do Kaizen é uma ferramenta viável para a implantação de melhorias contínuas. Nesse sentido, o objetivo deste estudo foi implantar o Kaizen em uma indústria de nutrição animal para obter diversas melhorias no processo produtivo desta empresa. $O$ método de pesquisa consistiu em um estudo de caso com aplicação dos passos propostos pela ferramenta Kaizen, o qual iniciou com a definição do mapa de fluxo de valor e seguiu com planos de ações para as melhorias propostas. Dentre os resultados, foram implantadas dez medidas de melhoria nos diferentes setores da empresa, as quais permitiram uma melhoria na produção de produtos para a nutrição animal. A implicação prática é o método de aplicação do Kaizen como ferramenta de melhoria contínua com o auxílio do mapa de fluxo de valor em uma empresa do ramo alimentício.

Palavras-chave: Indústria de alimentos; Ferramentas Lean; Mapa de fluxo de valor. 


\section{INTRODUÇÃO}

A demanda e a oferta por alimentos destinados à nutrição animal têm aumentado com o passar dos anos, fazendo com que as indústrias invistam cada vez mais nos processos produtivos para sobreviverem no mercado (Belik, 1994). O aumento do consumo de aves e suínos proporcionou significativo aumento no consumo de nutrição animal (Zen et al., 2015). Além dos investimentos em pesquisas e em novas tecnologias, a utilização de ferramentas de Lean Production tem auxiliado as empresas a produzirem mais e melhor e com menores custos, sendo um desses métodos o Kaizen (Awad; Shanshal, 2017). O emprego do Kaizen pode trazer para a organização uma considerável redução de desperdícios junto ao fluxo de materiais e informações, tendo como base melhorias contínuas dos processos.

$\mathrm{Na}$ aplicação do Kaizen também podem ser empregadas outras ferramentas de Lean, como o Just in Time e Kanban, com o intuito de atingir as metas desejadas e obter a melhoria contínua dos processos, especialmente quando relacionados à logística do processo produtivo (Matusova, 2016; Iwao, 2017).

As indústrias de nutrição animal, na sua maioria, contam com processos produtivos manuais e com pouca automatização. Assim, a implantação de melhorias com a utilização da ferramenta Kaizen tem de contar obrigatoriamente com a participação das pessoas envolvidas no processo de produção (García et al., 2014).

Entretanto, apesar do aumento da aplicação e dos benefícios da implantação de programas Kaizen, ainda existe uma lacuna no que diz respeito à documentação do projeto, implantação e resultados, bem como o que pode ser mais ou menos efetivo durante a implantação. Além disso, para implantar o Kaizen exige-se mão de obra qualificada e com a mente voltada à melhoria contínua (Glover et al., 2013).

Neste sentido, o objetivo desse estudo foi implantar o Kaizen em uma indústria de nutrição animal de Chapecó/SC com intuito de obter melhorias contínuas no processo produtivo desta organização.

\section{REVISÃO BIBLIOGRÁFICA}

\section{Principais ferramentas do sistema Toyota de produção}

O novo paradigma de reestruturação da indústria, em geral, a partir dos anos de 1970, foi o sistema Toyota ou 'toyotismo', o que também refletiu na indústria de alimentos. Para substituir o antigo modelo de produção em massa sur- giram as novas ideias de produção e eliminação de desperdícios (Ohno, 1997).

O Lean pode ser visto tanto como uma filosofia quanto como um método para planejamento e controle de operações. Seus princípios representam uma mudança radical em relação à prática tradicional da produção (Slack et al., 2009).

Entre as ferramentas utilizadas para eliminar o desperdício encontra-se o Just in Time (JIT). Ao contrário dos sistemas tradicionais que empurram a produção, o JIT é uma ferramenta que puxa a produção, ou seja, os produtos são produzidos a partir da demanda do cliente. Assim, o JIT entende que os erros são evitáveis e podem ser eliminados. Mesmo que a meta de estoque zero não seja alcançada, os movimentos de melhoria contínua podem resultar em índices reais de defeitos muito baixos (Corrêa; Gianesi, 2013).

Entre as principais ferramentas utilizadas para eliminar o desperdício encontra-se o Kanban, o qual transporta a informação de coleta, de transferência e de produção, vertical e lateralmente dentro da empresa. O Kanban define o que, quando e o quanto será produzido, impedindo totalmente a superprodução, não havendo necessidade de estoque extra (Ohno, 1997).

O Mapeamento de Fluxo de Valor (MFV) também se encontra entre as ferramentas utilizadas para eliminar o desperdício. Para criar um mapa de fluxo de valor deve-se fazer uma análise na procura de uma família de produtos que possa ser gerenciada individualmente. Com isso, elabora-se então uma matriz da família de produtos que agruparam os produtos a partir da sequência semelhante das etapas e das máquinas do processamento final (Rother; Shook, 2012).

Quando as empresas observam as próprias células ou linhas de produção é preciso aprimorar a visão para checar os três fluxos fundamentais, sendo eles:

a) A informação flui? Todos conhecem a meta de produção por hora? Com que rapidez os problemas e as normalidades são percebidos? O que acontece quando existem problemas ou anomalias?

b) O material flui? As peças em processo se movimentam de uma etapa que agrega valor diretamente para outra que também agrega valor?

c) Os operadores fluem? O trabalho do operador é repetitivo e consistente dentro de cada ciclo? 0 operador pode ir de maneira eficiente de uma etapa que agrega valor até a seguinte? (Rother; Shook, 2012).

Para que se possa compreender um mapeamento do fluxo de valor, deve-se primeiramente seguir os cinco passos 
indicados por Womack et al. (2004), que são: especificar o valor, identificar o fluxo de valor, definir o fluxo, puxar e aperfeiçoar.

Outra ferramenta é o Kaizen, que significa mudança para melhor ou melhoria contínua, sendo que surgiu no Japão após o final da $2^{\circ}$ Guerra Mundial, quando o país se encontrava praticamente destruído. O grande teórico do Kaizen enumera 10 princípios que devem ser seguidos nas empresas (Imai, 1992):

1) Eliminação dos desperdícios;

2) Melhorias incrementais de maneira contínua;

3) Envolvimento de todos os funcionários e gestores;

4) Melhorias de baixo custo baseadas em estratégia barata visando a aumentos de produtividade sem investimentos significativos;

5) Possibilidade de ser utilizado em qualquer lugar e não somente no Japão;

6) Gestão transparente, tornando os desperdícios e os problemas visíveis;

7) Foco no chão de fábrica, onde os ganhos podem ser potencializados;

8) Orientação para os processos;

9) Busca pelo treinamento;

10) Busca por nova mentalidade por meio do trabalho em equipe, de círculos de qualidade, de autodisciplina e do cultivo da sabedoria.

Em relação à eficiência na produção utilizando a metodologia Kaizen, a implantação definitiva e contínua deste método, visando estimular várias e sucessivas pequenas ações para a mudança de resultados, sem onerar as receitas financeiras, traz impactos positivos na motivação das equipes de trabalhadores (Rosa et al., 2010). Além disso, a metodologia Kaizen se traduz em melhoria do serviço ao cliente, permitindo maiores flexibilidade e rapidez na resposta às necessidades do mercado (Chahal et al., 2017).

A metodologia Kaizen vem sendo ainda aplicada, especialmente nos países em desenvolvimento, tais como o México (García et al., 2013), a Índia (Arya; Jain, 2014) e o Vietnã (Higuchi et al., 2015).

\section{MÉTODO DE PESQUISA}

\section{Delineamento da pesquisa}

Nesse estudo empregou-se a pesquisa qualitativa descritiva e a pesquisa documental, visando definir o problema de pesquisa e efetuar a coleta dos dados, tratando-os e analisando-os, bem como avaliando os resultados. A pesquisa se caracteriza também como sendo um estudo de caso.

Para um melhor entendimento do método de pesquisa utilizado para a implantação do Kaizen na empresa em estudo, foram seguidos os seguintes passos:

- Criação de equipes multidisciplinares

- Mapa de fluxo de valor atual (conhecimento do processo)

- Mapa de fluxo de valor futuro (proposição de meIhorias)

- Kaizen (implantação das melhorias)

- Cabe ressaltar que o conhecimento do processo já fazia parte da expertise dos autores.

\section{Estudo de caso}

A pesquisa foi realizada em uma indústria de rações para nutrição animal que produz núcleos, concentrados e rações fareladas, situada em Santa Catarina. Esta unidade conta com aproximadamente 100 funcionários, divididos em vários setores, com produção mensal de cerca de duas mil toneladas.

Em uma indústria de ração animal, as principais etapas envolvidas na fabricação são: armazenagem, transporte dos insumos, moagem, preparo dos micronutrientes, dosagem, mistura e ensaque. O processo de manusear, dosar, adicionar e misturar os nutrientes influencia diretamente no custo, na qualidade e na efetividade da ração a ser produzida. 0 processo de fabricação de rações se inicia pela recepção da matéria-prima, da qual se extraem amostras para análises. A descarga da matéria-prima é feita em moegas, as quais transportam internamente a matéria-prima. Após, os insumos são dosados, misturados e moídos. Ao mesmo tempo, outra equipe paralela dosa os micronutrientes que serão adicionados ao farelo já moído. No processo de fabricação de ração existem pontos críticos, tais como a recepção de matérias-primas, higienização dos equipamentos, das embalagens e dos manipuladores. Neste sentido, devem ser adotadas medidas preventivas com o intuito de evitar a contaminação da ração. 


\section{Processo de implantação}

Em um primeiro momento houve a participação e o envolvimento do supervisor da unidade, pois o comprometimento da alta administração na implantação de uma nova ferramenta de gestão industrial é fundamental. Obteve-se esta colaboração para o levantamento dos dados primários, para elaboração dos MFV e definição das dificuldades apresentadas pela unidade, bem como dos dados relacionados à linha de produção da empresa. Em seguida, foram montadas equipes multidisciplinares compostas pelo supervisor da unidade, funcionários envolvidos em áreas específicas, pessoal terceirizado na área de construção civil, controle de qualidade, entre outras áreas. Estas equipes foram montadas com o intuito de atuarem nas diversas etapas de fabricação do produto, visando a aplicação do Kaizen. Para que isto fosse possível, primeiramente, houve um treinamento e conscientização dos integrantes quanto ao Kaizen e a definição de líderes em cada equipe.

Com base na avaliação das equipes e do supervisor da unidade, o produto escolhido para a aplicação do Kaizen representou $9 \%$ da produção total durante o ano fiscal, o qual recebeu a denominação de "Produto A", dentre um total 480 tipos de produtos ativos. Isso demonstra que a empresa dispõe de uma grande variedade produtiva.

Para elaboração do MFV foram estudados os processos da linha de produção do "Produto A", com base em observação direta e com a utilização da Folha de Estudo do Processo (FEP), a qual possibilitou o registro de informações importantes em cada etapa do processo. A partir dessa análise foi possível definir as etapas do processo de fabricação do produto escolhido, o número real de operadores em cada função, quais operadores executavam as funções, as tomadas de tempo de cada etapa do processo, o tempo de máquina e todas as observações possíveis do ambiente de produção.

Após a análise detalhada do MFV atual, pela equipe multidisciplinar e pela administração, foram definidos os pontos que deveriam ser melhorados no processo produtivo. A partir disso, foi elaborado o MFV futuro, o qual contém os pontos de melhorias propostas destacados no mapa através de "balões".

Para cada uma dessas dez propostas de melhoria foram aplicados os Kaizens. O treinamento dos participantes das equipes ocorreu junto à sala de reuniões e treinamento da empresa, sendo realizados treinamentos técnicos, os quais consistiram na apresentação dos conceitos de Kaizen e o treinamento comportamental, o qual teve o objetivo de ampliar a percepção do ambiente, incentivando a criatividade dos envolvidos.

Na sequência, os Kaizen foram aplicados com os seguintes passos:
Conhecimento do problema: para isso foram realizados Brainstorming para melhor conhecimento das possíveis causas do problema e a partir disso, levantar oportunidades de melhorias. Em seguida foram elaborados os planos de ação $5 \mathrm{~W} 1 \mathrm{H}$, sendo que os custos não foram divulgados por orientação da empresa em estudo;

Aplicação das ações: nesta etapa foram aplicadas as ações descritas nos planos de ação, além do treinamento dos funcionários para a realização das tarefas conforme o planejado e o levantamento dos dados após a ação;

Verificação dos resultados: neste momento comparou-se o antes e depois das ações realizadas para verificar se foram efetivas ou não.

\section{RESULTADOS E DISCUSSÃO}

\section{Mapa de fluxo de valor atual e futuro}

O MFV atual serviu somente para o conhecimento do processo e o foco foi na localização dos principais pontos de geração de desperdícios na empresa. Este mapeamento de processo está representado pelo MFV futuro na Figura 1, na qual estão destacados os pontos onde foram empregados os Kaizen.

Como pode ser observado, dez pontos foram destacados para serem melhorados, sendo eles:

- Melhoria na sala de micro ingredientes;

- Melhoria do fluxo de MP (matérias-primas) para adição superior;

- Otimização de processo de macro ingredientes (pesagem de sal);

- Melhoria na gestão visual;

- Melhoria do processo de adição de MP;

- Otimização de paletização;

- Otimização do setor de ensaque;

- Redução de estoques de MP (matérias-primas) e PA (Produtos Acabados);

- Otimização do tempo de carga da expedição;

- Melhoria na gestão de assistência aos funcionários. 


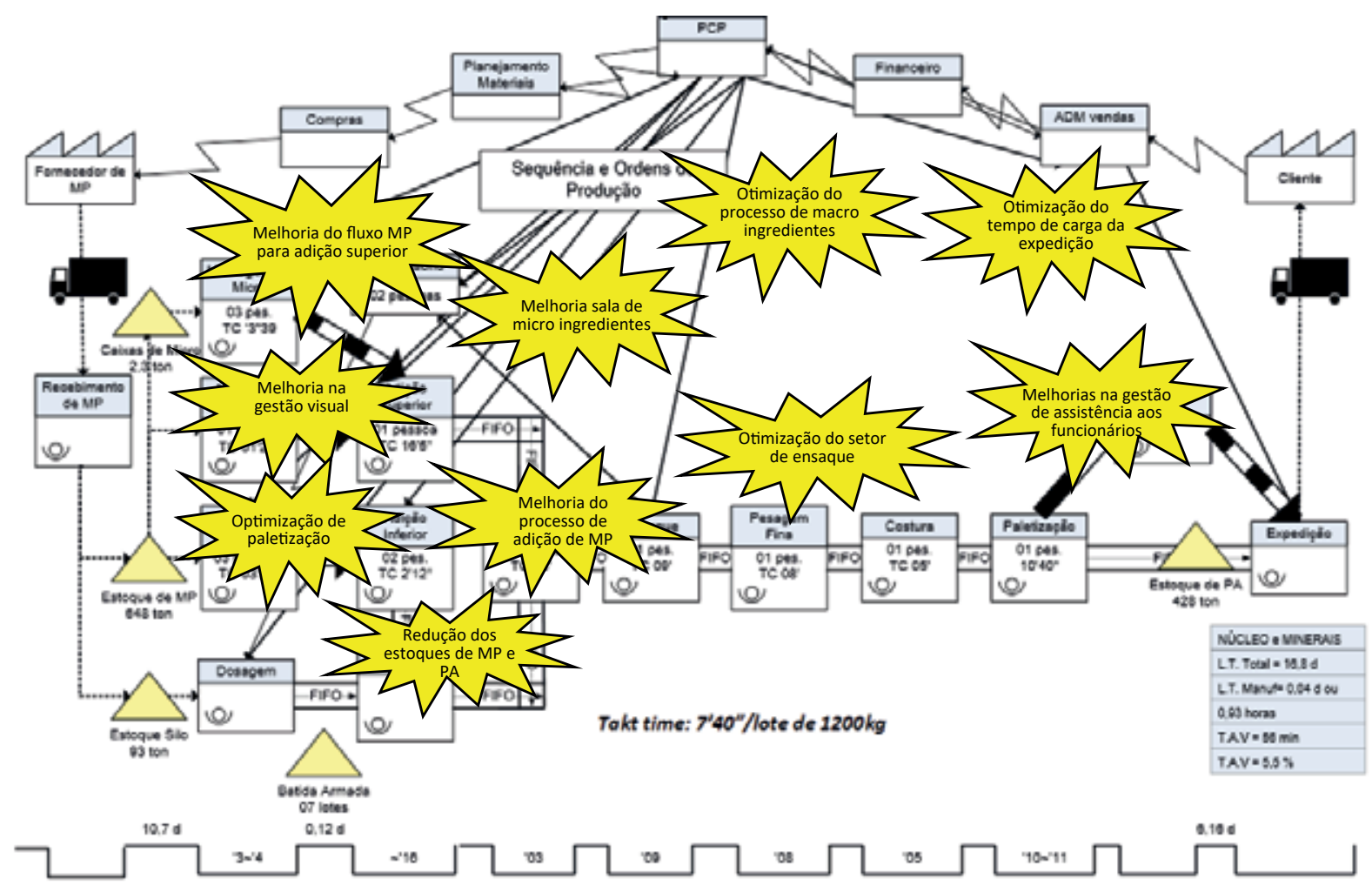

Figura 1. Mapa de Fluxo de Valor Futuro

Fonte: Os próprios autores

\section{Aplicação do Kaizen 1 e 2}

Para levantar os problemas na sala de micro ingredientes foi empregado o Brainstorming. Após este, definiu-se como prioridade de ações a modificação do layout da sala e otimização do processo de pesagem, que consiste na troca dos baldes de armazenagem de matéria-prima. A Figura 2 apresenta os planos de ação elaborados para estas ações prioritárias. Os planos de ação foram realizados no tempo estipulado nas duas principais ações.

\begin{tabular}{|c|c|c|c|c|c|}
\hline O Que & Quem & $\begin{array}{c}\text { Quan- } \\
\text { do }\end{array}$ & Como & Onde & Por Que \\
\hline $\begin{array}{c}\text { Mudan- } \\
\text { ça no } \\
\text { layout }\end{array}$ & $\begin{array}{c}\text { Gestor de } \\
\text { projetos } \\
\text { e equipe } \\
\text { manuten- } \\
\text { ção }\end{array}$ & $\begin{array}{c}2 \text { me- } \\
\text { ses }\end{array}$ & $\begin{array}{c}\text { Projetando } \\
\text { um novo } \\
\text { layout }\end{array}$ & $\begin{array}{c}\text { Sala } \\
\text { de } \\
\text { micro }\end{array}$ & $\begin{array}{c}\text { Excesso de } \\
\text { movimen- } \\
\text { tação de } \\
\text { pessoas e } \\
\text { materiais }\end{array}$ \\
\hline $\begin{array}{c}\text { Troca } \\
\text { dos } \\
\text { baldes }\end{array}$ & $\begin{array}{c}\text { Gestor da } \\
\text { produção }\end{array}$ & 15 dias & $\begin{array}{c}\text { Substi- } \\
\text { tuindo os } \\
\text { baldes de } \\
50 \text { kg por } \\
\text { caixas de } \\
20 \mathrm{~kg}\end{array}$ & $\begin{array}{c}\text { Sala } \\
\text { de } \\
\text { microso de } \\
\text { pesora } \\
\text { funcionários, } \\
\text { resultando } \\
\text { em proble- } \\
\text { mas ergonô- } \\
\text { micos }\end{array}$ \\
\hline
\end{tabular}

Figura 2. Planos de ação para a sala de micro ingredientes Fonte: Os próprios autores
Para a verificação dos resultados obtidos com as modificações fez-se um comparativo do antes e depois. Como pode ser observado na Figura 3a, a sala tem somente uma porta onde era feita a entrada e saída dos ingredientes, ocasionando um contra fluxo de matéria-prima, não estando de acordo com as normas de boas práticas de fabricação. Além disso, o fluxo da sala exigia do operador muitas caminhadas até o depósito para a retirada das matérias-primas.

Assim, pela mudança no layout da sala de micro ingredientes (Figura 3b), observou-se a redução de 35\% a caminhada diária do operador. Esta ação juntamente com a troca dos baldes diminui a fadiga diária dos operados e também a perda de matéria-prima por rasgo de sacarias e movimentação diária dos produtos.

\section{Aplicação do Kaizen 3}

O segundo Kaizen aplicado foi em relação ao fluxo inadequado de matéria-prima para adição superior. A partir das possíveis causas levantadas, verificou-se que as principais eram o layout e o elevador inadequado. Havia paredes e silos bloqueando o envio das matérias-primas alocadas em 


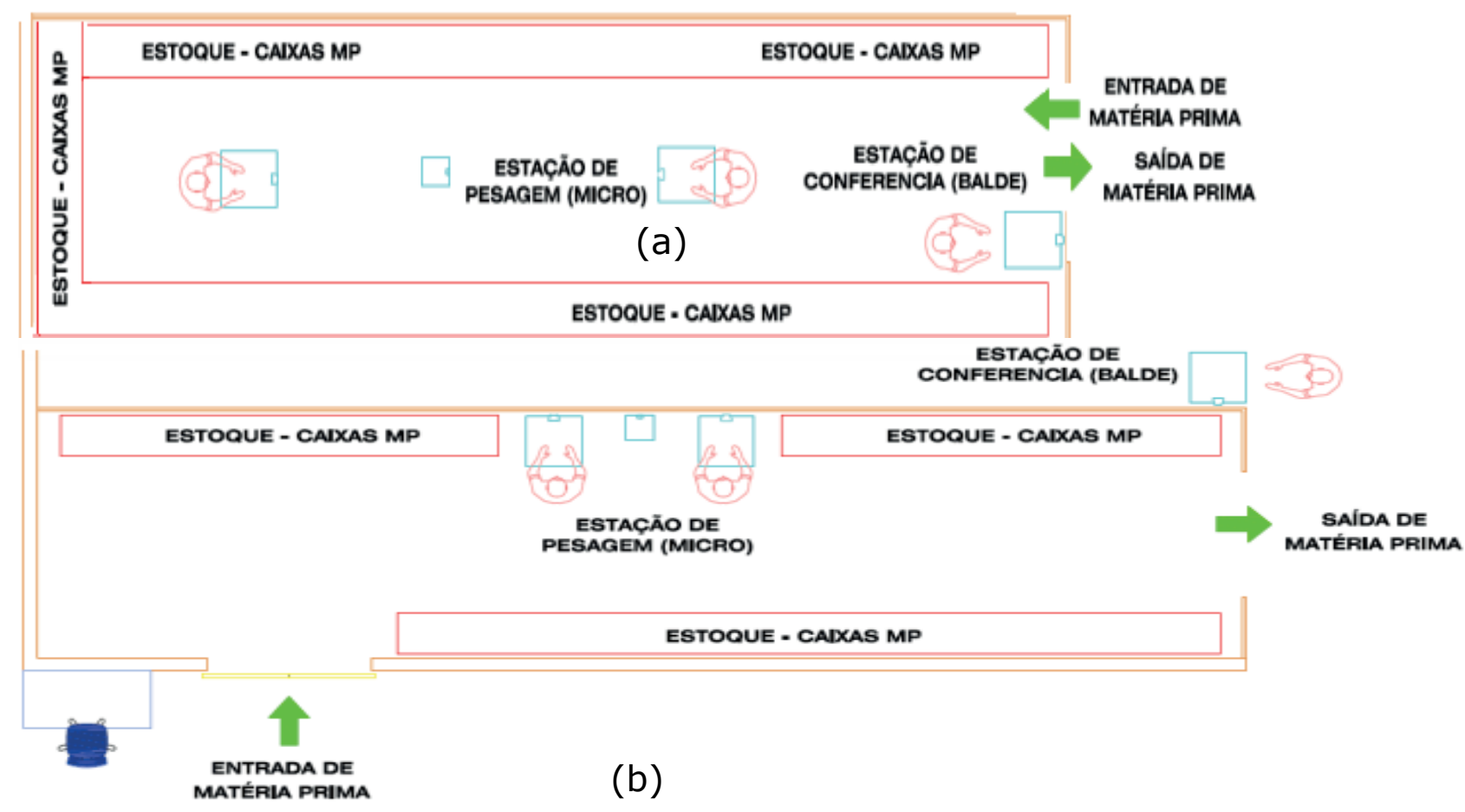

Figura 3. Layout da sala de micro ingredientes antes (a) e depois (b) das melhorias

Fonte: Os próprios autores

baldes ao elevador monta carga, pois a partir desse realizava-se a adição superior das matérias-primas ao sistema de mistura. O elevador, além deste estar em local inapropriado, era antigo, possuía apenas um cabo de aço, tornando-se uma operação insegura e não comportava o volume de trabalho. A Figura 4 apresenta os planos de ação para estas causas.

\begin{tabular}{|c|c|c|c|c|c|}
\hline O Que & Quem & $\begin{array}{c}\text { Quan- } \\
\text { do }\end{array}$ & Como & Onde & Por Que \\
\hline $\begin{array}{c}\text { Mudan- } \\
\text { ça no } \\
\text { layout }\end{array}$ & $\begin{array}{c}\text { Gestor } \\
\text { de proje- } \\
\text { tos }\end{array}$ & $\begin{array}{c}3 \text { me- } \\
\text { ses }\end{array}$ & $\begin{array}{c}\text { Projetan- } \\
\text { do um } \\
\text { novo la- } \\
\text { yout em } \\
\text { um novo } \\
\text { local }\end{array}$ & $\begin{array}{c}\text { Sala } \\
\text { de } \\
\text { macro }\end{array}$ & $\begin{array}{c}\text { Projeto da } \\
\text { fábrica anti- } \\
\text { go com pa- } \\
\text { redes e silos } \\
\text { bloqueando } \\
\text { o acesso }\end{array}$ \\
\hline $\begin{array}{c}\text { Insta- } \\
\text { lação } \\
\text { de um } \\
\text { novo } \\
\text { eleva- } \\
\text { dor }\end{array}$ & $\begin{array}{c}\text { Ges- } \\
\text { tor de } \\
\text { projetos } \\
\text { e equipe } \\
\text { de ma- } \\
\text { nutenção }\end{array}$ & 3 me- \\
ses & $\begin{array}{c}\text { Substi- } \\
\text { tuindo o } \\
\text { elevador }\end{array}$ & $\begin{array}{c}\text { Sala } \\
\text { de } \\
\text { macro }\end{array}$ & $\begin{array}{c}\text { Elevador } \\
\text { antigo, } \\
\text { acionamento } \\
\text { manual e in- } \\
\text { seguro com } \\
\text { somente um } \\
\text { cabo de aço }\end{array}$ \\
\hline
\end{tabular}

Figura 4. Planos de ação para melhoria do fluxo de MP na adição superior

Fonte: Os próprios autores

Após implantação dos planos de ação foi possível a verificação dos resultados obtidos com as modificações realiza- das. A Figura 5 apresenta um comparativo do antes e depois no fluxo de MP para a adição superior. Pode-se perceber a grande diferença nos fluxos de MP até o elevador antes e após o novo layout. Este novo layout representou uma redução de aproximadamente $90 \%$ no caminho percorrido, pois o novo elevador ficou bem próximo da sala de micro, fazendo com que os funcionários pudessem colocar os baldes de micro ingredientes direto no elevador, a uma distância de 20 $\mathrm{m}$. Antes da melhoria, o funcionário percorria em torno de $200 \mathrm{~m}$ para chegar ao elevador. Observou-se também que com a instalação do novo elevador monta carga, passou-se a dispor de maior espaço para a manipulação das matérias-primas, além da segurança na execução das tarefas.

\section{Aplicação do Kaizen 4}

$O$ terceiro Kaizen foi em relação ao processo ineficaz de macro pesagem de ingredientes, no caso, pesagem de sal em sacos de $50 \mathrm{~kg}$. Para suprir esses problemas realizou-se um Brainstorming, sendo que as principais ideias levantadas foi melhorar a ergonomia do trabalhador através do Kaizen (Rodriguez; Lopez, 2012), utilizando neste caso um sistema de pesagem de sal automático. A partir destas discussões, elaborou-se um plano de ação para a realização das melhorias nesta etapa do processo, demonstrado na Figura 6. 


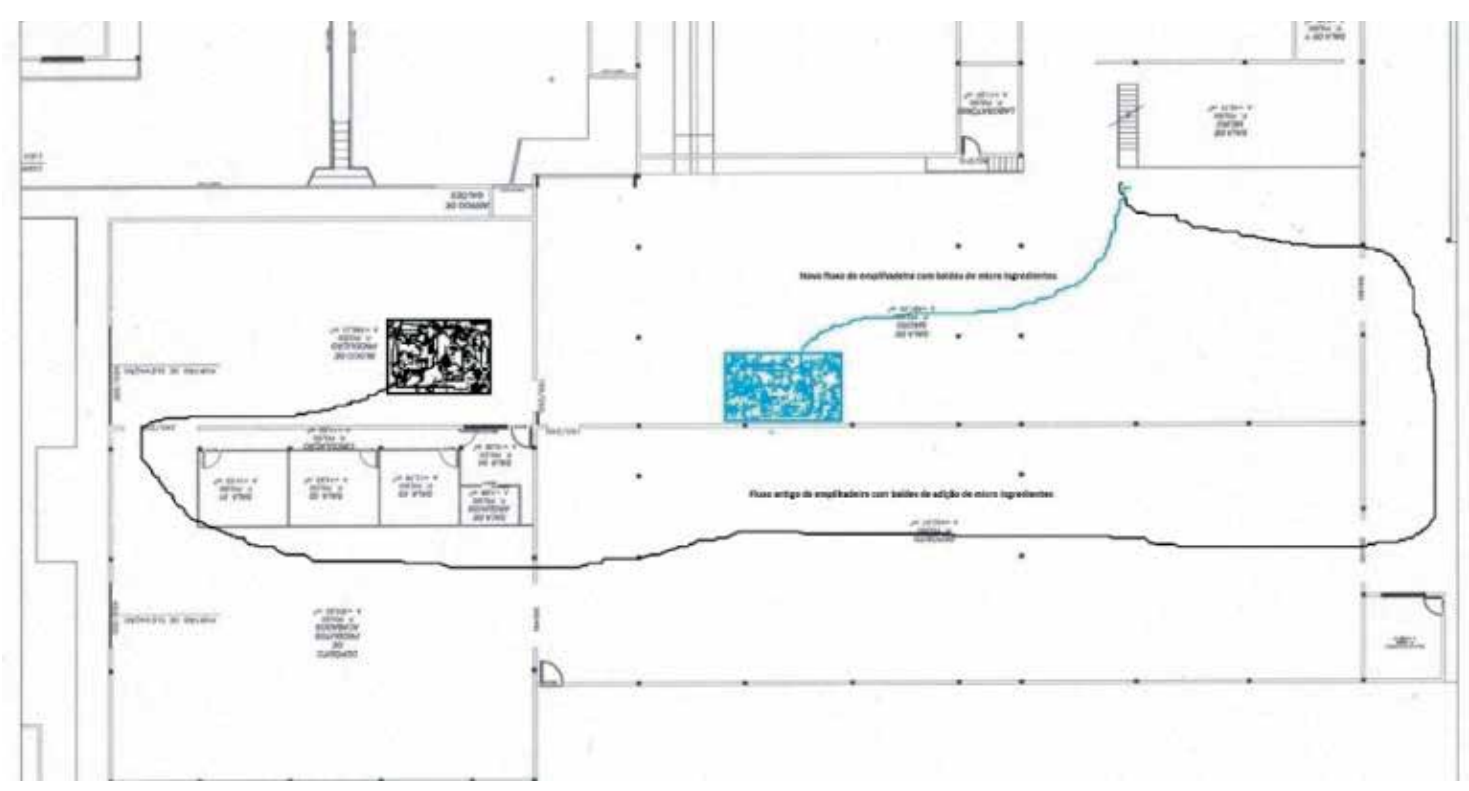

Figura 5. Fluxo antes das melhorias (preto) e após a aplicação de melhorias (azul) Fonte: Os próprios autores

\begin{tabular}{|c|c|c|c|c|c|}
\hline O Que & $\begin{array}{c}\text { Por } \\
\text { Que }\end{array}$ & Quem & Onde & $\begin{array}{c}\text { Quan- } \\
\text { do }\end{array}$ & Como \\
\hline $\begin{array}{c}\text { Melhorar o } \\
\text { sistema de } \\
\text { pesagem } \\
\text { de sal }\end{array}$ & $\begin{array}{c}\text { Me- } \\
\text { Ihorar } \\
\text { o fluxo } \\
\text { de } \\
\text { produ- } \\
\text { ção }\end{array}$ & $\begin{array}{c}\text { Super- } \\
\text { visor da } \\
\text { unidade }\end{array}$ & $\begin{array}{c}\text { Setor } \\
\text { de } \\
\text { produ- } \\
\text { ção }\end{array}$ & $\begin{array}{c}3 \text { me- } \\
\text { ses }\end{array}$ & $\begin{array}{c}\text { Comprar a } \\
\text { balança big } \\
\text { bag e treinar } \\
\text { a equipe. }\end{array}$ \\
\hline
\end{tabular}

Figura 6. Planos de ação para a melhoria do processo de pesagem de sal

Fonte: Os próprios autores

Com a instalação do sistema de pesagem de sal big bag, passou-se a pesar até $1.000 \mathrm{~kg}$ por vez, aumentando a produção total, reduzindo os riscos à saúde dos funcionários e otimizando o tempo do processo.

\section{Aplicação do Kaizen 5}

Conforme definido no MFV, constatou-se a necessidade de melhorias na infraestrutura da empresa para melhoria dos processos e conforto para as partes interessadas. A Figura 7 apresenta a nova guarita, representando uma considerável melhora no ambiente da empresa, onde a sala da recepção dispõe de janelas em vidro, o que melhora a visão dos guardas e dos funcionários que realizam as checagens de notas fiscais e conferência de peso na balança rodoviária.
Além disso, foram feitos consertos em geral, melhorias no banheiro e instalação de um aparelho de televisão.

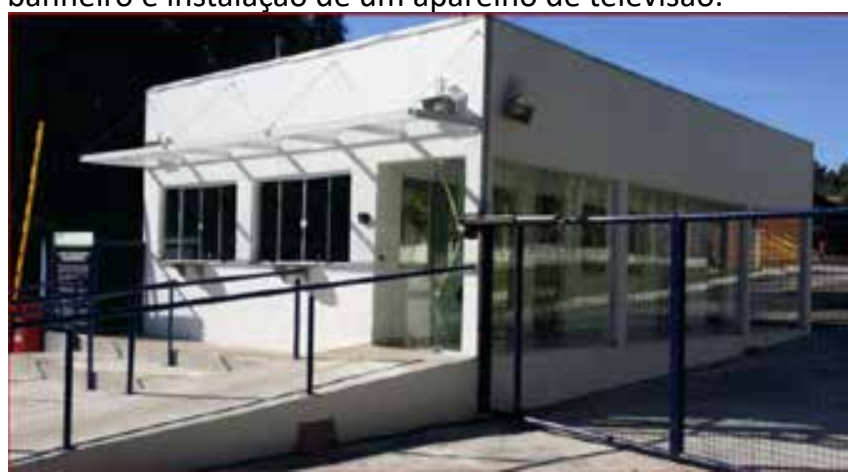

Figura 7. Acesso à empresa após a aplicação de melhorias Fonte: Os próprios autores

\section{Aplicação do Kaizen 6}

Conforme o MFV, mostrava-se necessário otimizar o setor de ensaque, sendo que esta foi uma das tarefas que exigiram mais tempo, devido à demora para a compra do equipamento necessário e treinamento dos funcionários para utilizá-lo. A Figura 8 apresenta os planos de ação elaborados a partir das ações levantadas. 


\begin{tabular}{|c|c|c|c|c|c|}
\hline O Que & Quem & $\begin{array}{c}\text { Quan- } \\
\text { do }\end{array}$ & Como & Onde & Por Que \\
\hline $\begin{array}{c}\text { Reduzir o } \\
\text { gargalo no } \\
\text { setor de } \\
\text { ensaque }\end{array}$ & $\begin{array}{c}\text { Gestor } \\
\text { de } \\
\text { proje- } \\
\text { tos }\end{array}$ & $\begin{array}{c}6 \text { me- } \\
\text { ses }\end{array}$ & $\begin{array}{c}\text { Com } \\
\text { equipa- } \\
\text { mentos } \\
\text { eficazes }\end{array}$ & $\begin{array}{c}\text { Setor } \\
\text { de } \\
\text { ensa- } \\
\text { que }\end{array}$ & $\begin{array}{c}\text { Ampliar a } \\
\text { veloci- } \\
\text { dade do } \\
\text { ensaque }\end{array}$ \\
\hline $\begin{array}{c}\text { Instalar } \\
\text { máquina } \\
\text { semiauto- } \\
\text { mática de } \\
\text { ensaque }\end{array}$ & $\begin{array}{c}\text { Gestor } \\
\text { de } \\
\text { proje- } \\
\text { tos }\end{array}$ & $\begin{array}{c}6 \text { me- } \\
\text { ses }\end{array}$ & $\begin{array}{c}\text { Adqui- } \\
\text { rindo } \\
\text { máquina }\end{array}$ & $\begin{array}{c}\text { Setor } \\
\text { de } \\
\text { ensa- } \\
\text { que }\end{array}$ & $\begin{array}{c}\text { Reduzir } \\
\text { desperdí- } \\
\text { cios }\end{array}$ \\
\hline
\end{tabular}

Figura 8. Planos de ação para otimizar o ensaque Fonte: Os próprios autores

A nova estrutura contemplou uma máquina semiautomática, que opera com cinco funcionários (antes eram nove funcionários), além disso, a capacidade produtiva foi $30 \%$ superior, o que permitiu uma margem para crescimento do processo e da empresa, reduzindo o gargalo neste setor.

\section{Aplicação do Kaizen 7, 8 e 9}

De acordo com o MFV Futuro, existia na empresa a necessidade de melhorias na área de estoque e logística, relacionadas à otimizar a paletização, redução de estoques de MP e PA, além da redução do tempo de carga da expedição. Foi utilizada a técnica do Brainstorming para obter ideias junto às pessoas envolvidas nesta atividade e a elaboração do plano de ação (Figura 9).

A quantidade de sacaria sobre o pallet foi a máxima possível em relação ao potencial de utilização, passando de cinco sacos com $30 \mathrm{~kg}$ cada para sete sacos com $30 \mathrm{~kg}$ cada. Esta melhoria resultou em ganho de tempo, visto que foi transportada maior quantidade de materiais por pallet. Além disso, obteve-se maior aproveitamento da mão-de-obra e mais segurança no transporte, pois as sacarias foram recobertas com filme plástico.

Para a redução de estoque de MP foram empregadas as ferramentas JIT e Kanban. Com a utilização do JIT houve uma na redução da quantidade de MP em estoque, resultando em $30 \%$ mais de espaço de estocagem, sendo considerada uma porcentagem expressiva para o volume de produtos produzidos na empresa. Já a utilização do Kanban resultou na compra de MP realmente necessárias, diminuindo a geração estoques excessivos.

Em relação aos PA, além da redução dos estoques, foi observado a necessidade de aumento da altura do ambiente onde ficavam armazenados os produtos, pois muitas vezes, a empilhadeira acabava batendo no teto do local. Assim, foi retirado o teto antigo e realizada a construção de um novo teto mais alto, de forma que a empilhadeira pudesse retirar os materiais no topo das prateleiras sem que tivesse contato com o teto. Também foi melhorada a iluminação do local e realizada uma disposição dos produtos acabados de maneira mais organizada. Com isso, observou-se uma diminuição do tempo para encontrar o produto desejado para expedição. A Figura 10 mostra o estoque antes (10a) e depois (10b) das melhorias.

\begin{tabular}{|c|c|c|c|c|c|}
\hline O Que & Quem & $\begin{array}{l}\text { Quan- } \\
\text { do }\end{array}$ & Como & Onde & Por Que \\
\hline $\begin{array}{l}\text { Aumentar a } \\
\text { segurança } \\
\text { no manu- } \\
\text { seio dos } \\
\text { pallets }\end{array}$ & $\begin{array}{l}\text { Gestor } \\
\text { de } \\
\text { proje- } \\
\text { tos }\end{array}$ & $\begin{array}{c}2 \text { me- } \\
\text { ses }\end{array}$ & $\begin{array}{l}\text { Treinan- } \\
\text { do os } \\
\text { funcio- } \\
\text { nários }\end{array}$ & $\begin{array}{l}\text { Setor } \\
\text { de } \\
\text { Pro- } \\
\text { dução }\end{array}$ & $\begin{array}{c}\text { Evitar } \\
\text { acidentes } \\
\text { de trabalho } \\
\text { e perda de } \\
\text { materiais }\end{array}$ \\
\hline $\begin{array}{l}\text { Reduzir a } \\
\text { subutili- } \\
\text { zação os } \\
\text { pallets }\end{array}$ & $\begin{array}{l}\text { Gestor } \\
\text { de } \\
\text { proje- } \\
\text { tos }\end{array}$ & $\begin{array}{c}2 \text { me- } \\
\text { ses }\end{array}$ & $\begin{array}{l}\text { Treinan- } \\
\text { do os } \\
\text { funcio- } \\
\text { nários }\end{array}$ & $\begin{array}{l}\text { Setor } \\
\text { de } \\
\text { Pro- } \\
\text { dução }\end{array}$ & $\begin{array}{c}\text { Ocupar } \\
\text { maior área } \\
\text { na superfície } \\
\text { dos pallets }\end{array}$ \\
\hline $\begin{array}{l}\text { Transpor- } \\
\text { tar maior } \\
\text { quantidade } \\
\text { de materiais } \\
\text { nos pallets }\end{array}$ & $\begin{array}{l}\text { Gestor } \\
\text { de } \\
\text { proje- } \\
\text { tos }\end{array}$ & $\begin{array}{c}2 \text { me- } \\
\text { ses }\end{array}$ & $\begin{array}{l}\text { Treinan- } \\
\text { do os } \\
\text { funcio- } \\
\text { nários }\end{array}$ & $\begin{array}{l}\text { Setor } \\
\text { de } \\
\text { Pro- } \\
\text { dução }\end{array}$ & $\begin{array}{l}\text { Transportar } \\
\text { o máximo de } \\
\text { sacos com } 30 \\
\text { kg ao invés } \\
\text { de } 5 \text { sacos }\end{array}$ \\
\hline $\begin{array}{l}\text { Reduzir o } \\
\text { Estoque de } \\
\text { MP e PA }\end{array}$ & $\begin{array}{l}\text { Gestor } \\
\text { de } \\
\text { proje- } \\
\text { tos }\end{array}$ & $\begin{array}{c}2 \text { me- } \\
\text { ses }\end{array}$ & $\begin{array}{l}\text { Implan- } \\
\text { tando o } \\
\text { Just in } \\
\text { Time e } \\
\text { Kanban. }\end{array}$ & $\begin{array}{l}\text { Setor } \\
\text { de } \\
\text { MP e } \\
\text { PA }\end{array}$ & $\begin{array}{c}\text { Reduzir os } \\
\text { desperdícios } \\
\text { de tempo e } \\
\text { espaço de } \\
\text { estocagem. }\end{array}$ \\
\hline $\begin{array}{c}\text { Mudar a } \\
\text { estrutura do } \\
\text { ambiente do } \\
\text { estoque de } \\
\text { PA. }\end{array}$ & $\begin{array}{l}\text { Equipe } \\
\text { de } \\
\text { cons- } \\
\text { trução } \\
\text { civil }\end{array}$ & $\begin{array}{c}2 \text { me- } \\
\text { ses }\end{array}$ & $\begin{array}{l}\text { Aumen- } \\
\text { tando } \\
\text { a altura } \\
\text { do teto. }\end{array}$ & $\begin{array}{l}\text { Esto- } \\
\text { que } \\
\text { de PA }\end{array}$ & $\begin{array}{c}\text { Evitar aci- } \\
\text { dentes }\end{array}$ \\
\hline $\begin{array}{l}\text { Reduzir o } \\
\text { tempo de } \\
\text { localização } \\
\text { dos produ- } \\
\text { tos } \\
\end{array}$ & $\begin{array}{l}\text { Gestor } \\
\text { de } \\
\text { proje- } \\
\text { tos }\end{array}$ & $\begin{array}{c}2 \text { me- } \\
\text { ses }\end{array}$ & $\begin{array}{l}\text { Orga- } \\
\text { nizar e } \\
\text { separar } \\
\text { os pro- } \\
\text { dutos }\end{array}$ & $\begin{array}{l}\text { Setor } \\
\text { de } \\
\text { expe- } \\
\text { dição }\end{array}$ & $\begin{array}{l}\text { Reduzir o } \\
\text { tempo de } \\
\text { expedição }\end{array}$ \\
\hline $\begin{array}{c}\text { Tornar o } \\
\text { processo de } \\
\text { expedição } \\
\text { mais rápido }\end{array}$ & $\begin{array}{l}\text { Gestor } \\
\text { de } \\
\text { proje- } \\
\text { tos }\end{array}$ & $\begin{array}{c}2 \text { me- } \\
\text { ses }\end{array}$ & $\begin{array}{l}\text { Pratelei- } \\
\text { ras em } \\
\text { cores }\end{array}$ & $\begin{array}{l}\text { Setor } \\
\text { de } \\
\text { expe- } \\
\text { dição }\end{array}$ & $\begin{array}{c}\text { Reduzir } \\
\text { desperdícios } \\
\text { de tempo }\end{array}$ \\
\hline $\begin{array}{l}\text { Otimizar o } \\
\text { trabalho dos } \\
\text { operadores } \\
\text { e empilha- } \\
\text { deiras }\end{array}$ & $\begin{array}{l}\text { Gestor } \\
\text { de } \\
\text { proje- } \\
\text { tos }\end{array}$ & $\begin{array}{c}2 \text { me- } \\
\text { ses }\end{array}$ & $\begin{array}{l}\text { Criar } \\
\text { uma } \\
\text { área de } \\
\text { picking }\end{array}$ & $\begin{array}{l}\text { Setor } \\
\text { de } \\
\text { expe- } \\
\text { dição }\end{array}$ & $\begin{array}{c}\text { Reduzir carga } \\
\text { de trabalho } \\
\text { do operador } \\
\text { e empilha- } \\
\text { deiras }\end{array}$ \\
\hline
\end{tabular}

Figura 9. Plano de ação para melhorias na área de estoque e logística da empresa

Fonte: Os próprios autores 


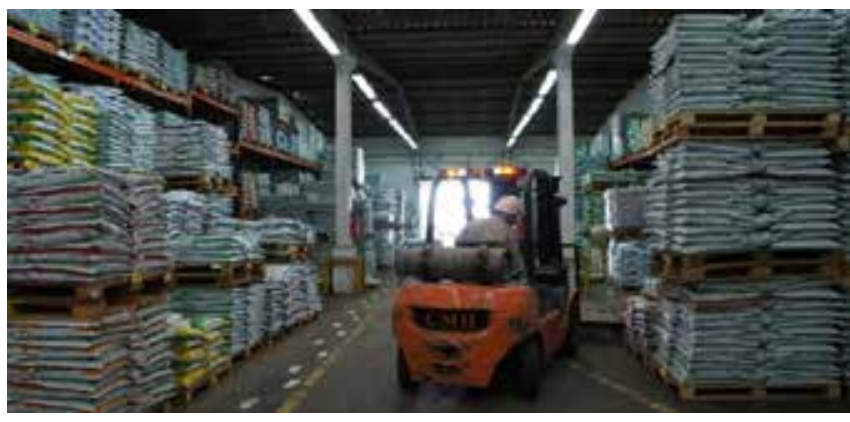

(a)

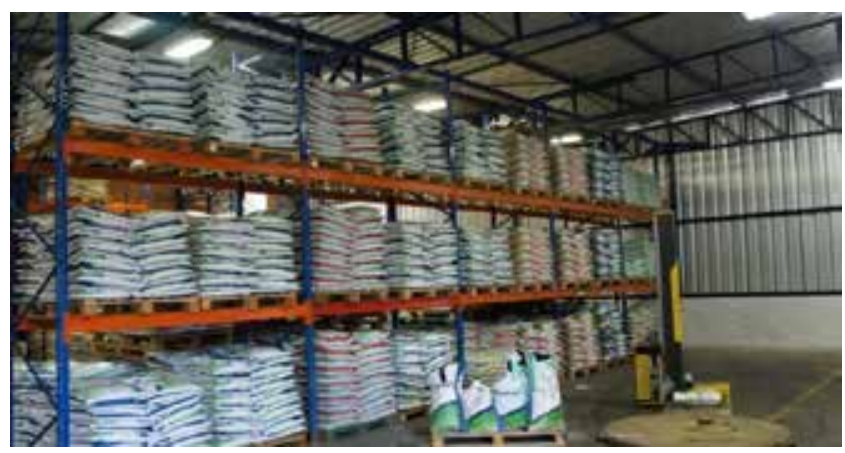

(b)

Figura 10. Estoque de PA antes (a) e depois (b) das melhorias Fonte: Os próprios autores

Em relação ao tempo de carga da expedição, neste setor, os produtos ficavam, na maioria das vezes, expostos em pallets soltos, sem a devida organização e separação, causando a perda de tempo para a localização correta dos produtos e demora na demanda de separação. Por isso, no setor de expedição foi criada uma área de picking, onde são armazenados os produtos excedentes de carregamentos anteriores, que poderão ser utilizados nos próximos carregamentos.

\section{Aplicação do Kaizen 10}

O décimo Kaizen se refere à melhoria na gestão de assistência aos funcionários. A aplicação do conceito de gestão de pessoas atualmente é cada vez mais exigido junto às organizações. Por isso, durante a implantação do Kaizen na empresa, os funcionários levantaram a necessidade de uma nova sala de controle de qualidade, de uma nova sala de saúde e segurança do trabalho, bem como a construção de uma sala de reuniões e treinamento, que ainda não existia na empresa, visando melhorias na infraestrutura aos funcionários.

Foi identificado que era necessária a construção de uma nova sala para o controle de qualidade, pois a sala anterior era confeccionada em divisórias Eucatex, fora do princípio de segurança de alimentos, sendo que esse tipo de ambiente deveria estar de acordo com as normas e exigências do Ministério da Agricultura, Pecuária e Abastecimento (Brasil,
2009). Assim, foi construída uma nova sala para o controle de qualidade dos produtos na qual as amostras passaram a ficar em um ambiente de acordo com as normas do MAPA, ou seja, com materiais duráveis que não propagam umidade, sendo a sala ampla, clara e de fácil acesso aos funcionários.

Em relação à sala da segurança e saúde do trabalho, verificou-se que havia pouco espaço para os técnicos exercerem suas atividades e ficava localizada no setor de manutenção, onde eram armazenados inadequadamente materiais, o que trazia desconforto ao trabalho dos técnicos. Assim, foi construída uma sala para a segurança e saúde do trabalho junto ao setor de produção, além da construção de uma sala de reuniões e treinamento na empresa.

\section{CONCLUSÃO}

Após a análise dos dados obtidos, foi possível verificar que a implantação da ferramenta Kaizen em uma indústria de nutrição animal, na cidade de Chapecó, Santa Catarina, atingiu os objetivos propostos, uma vez que contribuiu, de um modo geral, para a melhoria da cadeia produtiva desta organização. O mapeamento do fluxo de processo se mostrou uma poderosa ferramenta para o conhecimento do processo de fabricação do produto $A$, de forma que permitiu, a partir das informações coletadas, definir as melhorias, as quais foram obtidas aplicando-se a ferramenta Kaizen.

Todas as oportunidades de melhorias foram trabalhadas com êxito, pois houve redução dos tempos de processo e redução de estoques de materiais, bem como melhorias na ergonomia dos funcionários, redução de desperdícios de materiais, movimentos, recursos, tempo, entre outras ações.

Além disso, ficou evidente que as pessoas envolvidas no processo de fabricação dos produtos são fundamentais para que se possa aplicar um novo método de gestão, pois mudanças sempre geram desconfianças. Sendo assim, foi preciso demonstrar a importância da ferramenta Kaizen, enfatizar as melhorias obtidas, incentivando e contando sempre com a ajuda dos colaboradores. Ressalta-se ainda que os resultados obtidos na empresa são o início da implantação da ferramenta Kaizen e que as melhorias devem ser contínuas, como preconiza o fundamento desta ferramenta.

\section{REFERÊNCIAS}

Arya, A. K.; Jain, S. K. 2014. Impacts of Kaizen in a small-scale industry of India: a case study. International Journal of Lean Six Sigma 5, 1:22-44. https://doi.org/10.1108/ IJLSS-03-2013-0019

Awad, M.; Shanshal, Y. A. 2017. Utilizing Kaizen process and DFSS methodology for new product development. Interna- 
tional Journal of Quality \& Reliability Management 34, 3:378394. https://doi.org/10.1108/IJQRM-09-2014-0139

Belik, W. 1994. Agroindústria e reestruturação industrial no Brasil: elementos para uma avaliação. Cadernos de Ciência \& Tecnologia 11, 1/3:58-75. http://dx.doi.org/10.35977/01041096.cct1994.v11.9026

Chahal, V.; Narwal, M. 2017. Impact of lean strategies on different industrial lean wastes. International Journal of Theoretical and Applied Mechanics 12, 2:275-286.

Corrêa, H. L.; Gianesi, I. G. N. 2013. Just in time, MRP II E OPT: um enfoque estratégico. Atlas, São Paulo.

García, J. L. et al. 2014. Human critical success factors for kaizen and its impacts in industrial performance. The International Journal of Advanced Manufacturing Technology 70, 9:2187-2198. https://doi.org/10.1007/s00170-013-5445-4

García, J. L. et al. 2013. Critical success factors for Kaizen implementation in manufacturing industries in Mexico. The International Journal of Advanced Manufacturing Technology 68, 1:537-545. https://doi.org/10.1007/S00170-013-4750-2

Glover, W. J. et al. 2013. Characteristics of established kaizen event programs: an empirical study. International Journal of Operations \& Production Management 33, 9:1166-1201. https://doi.org/10.1108/IJOPM-03-2011-0119

Higuchi, Y. et al. 2015. Sustained impacts of Kaizen training. Journal of Economic Behavior \& Organization 120, 189-206. https://doi.org/10.1016/j.jebo.2015.10.009

Imai, M. 1992. Kaizen: a estratégia para o sucesso competitivo. 4th ed., IMAM, São Paulo.
Iwao, S. 2017. Revisiting the existing notion of continuous improvement (Kaizen): literature review and field research of Toyota from a perspective of innovation. Evolutionary and Institutional Economics Review 14, 1:29-59. https://doi. org/10.1007/s40844-017-0067-4

Matusova, D. 2016. The improvement of logistics processes through Kaizen and six sigma. Transport \& Logistics 16, 38/39:1-6.

Ohno, T. 1997. O Sistema Toyota de Produção: além da produção em larga escala. Bookman, Porto Alegre.

Rodriguez, M. A.; Lopez, L. F. 2012. Kaizen and ergonomics: the perfect marriage. Work 41, 964-967. https://doi.org/10.3233/ WOR-2012-0271-964

Rosa, H. et al. 2010. Controle de estoque por revisão contínua e revisão periódica: uma análise comparativa utilizando simulação. Production 20, 4:626-638. http://dx.doi.org/10.1590/ S0103-65132010005000052

Rother, M.; Shook, J. 2012. Aprendendo a enxergar: mapeando o fluxo de valor para agregar valor e eliminar o desperdício. Lean Institute Brasil, São Paulo.

Slack, N. et al. 2009. Administração da Produção. 3. ed. Atlas, São Paulo.

Womack, J. et al. 2004. A máquina que mudou o mundo. Campus, Rio de Janeiro.

Zen, S. et al. 2015. Setor avícola em 2015 e perspectivas para 2016. Informativo CEPEA, 4. http://cepea.esalq.usp.br/frango/custos/2015/03Set_Dez.pdf

Recebido: 07 fev. 2020

Aprovado: 02 nov. 2020

DOI: 10.20985/1980-5160.2020.v15n3.1609

Como citar: Bresciani, J.B.; Bianchet, F.S.; Zanetti, M. et al. (2020). O Kaizen como sistema de melhoria contínua: um estudo de caso em uma indústria de nutrição animal. Revista S\&G 15, 3, 213-222. https://revistasg.emnuvens. com.br/sg/article/view/1609 